

\section{Artigo Especial}

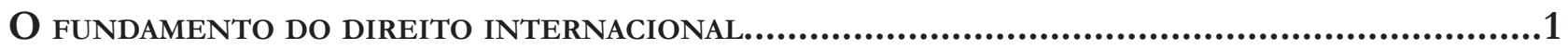
Alfred Verdross

\section{Proteção Internacional dos Direitos Humanos}

INDIGENOUS RIGHTS MOVEMENT: IS THE SAME NEEDED TO PREVENT CONTINUED HUMAN RIGHTS VIOLATIONS OF THE MENTALLY ILL

Liesel LeCates

O Discurso DAS DROGAS CONSTRUído PELO DIREITO INTERNACIONAL

Camila Soares Lippi

O ESTADO DEMOCRÁTICO DE DIREITO LAICO E A "NEUTRALIDADE" ANTE A INTOLERÂNCIA RELIGIOSA

Antonio Baptista Gonçalves

UM DiREITO SEM ESTADO? DiREITOS humanos E A FORMAÇÃo DE UM NOVO QUADRo NORMATIVO GLOBAL .87

Anderson Vichinkeski Teixeira e Rafael Köche

\section{Direito Humanitário}

The U.N. Standard Minimum Rules for the Treatment of Prisoners and North Korea: How North Korea is Violating these Rules with its Operation of the Yodok Concentration CAMP.

Tom Theodore Papain

U.S. Institutionalized Torture with Impunity: Examining Rape and Sexual Abuse in Custody Through the ICTY JurisprudenCE. 126 Allison Rogne 
Abduction, Torture, Interrogation: An Argument Against Extraordinary RendiTION

Kaitlyn E. Tucker

United States and European Union approaches to the death penalty: America SHOULD CONSIDER A NEW PERSPECTIVE 155 Katie R Hill

Tudo DE NOVO NO FRONT: MONUSCO, UMA NOVA ERA NAS PEACEKEEPING OPERATIONS? .169 Priscila Fett

A ADMINISTRAÇÃo DE TERRITÓRIOS OCUPADOS: INDETERMINAÇÃO DAS NORMAS DE DIREITO INTERNACIONAL HUMANITÁRIO?. 184 João Henrique Ribeiro Roriz, Fabia Fernandes Carvalho Veçoso e Lucas da Silva Tasquetto

THE (IN)APPLICABILITY OF THE STATUTE OF REFUGEES TO ENVIRONMENTALLY DISPLACED PERSONS 197 Maria Cláudia da Silva Antunes de Souza e Lucas de Melo Prado

\section{Sistema Interamericano de Direitos Humanos}

A contribuição da Comissão Interamericana de Direitos Humanos para o acesso À jus-

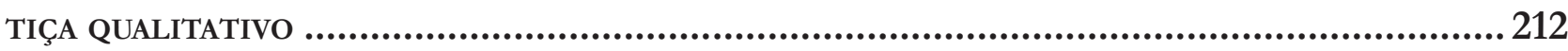
Márcio Antônio de Oliveira Filho, Ana Caroline Portes de Oliveira, Jéssica Galvão Chaves e Warlen Soares Teodoro

A executividade das sentenças da Corte Interamericana de Direitos Humanos no

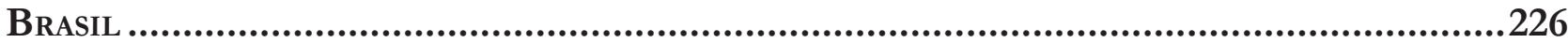

Augusto César Leite de Resende

A efetividade do ativismo jurídico transnacional no Sistema Interamericano de DiREITOS HuMANOS: UMA ANÁLISE A PARTIR DE CASOS CONTRA O BRASIL .................................238 Renata Mantovani de Lima e Lucélia de Sena Alves

O Processo e o Direito Coletivo no Sistema Interamericano de Direitos Humanos: UMA ANÁLISE COM BASE NA JURISPRUDÊNCIA INTERNACIONAL ...........................................250 Laercio Dias Franco Neto e Dafne Fernandez de Bastos 
CORTE INTERAMERICANA DE DIREITOS HUMANOS: OPINIÃo CONSULTIVA 4/84 - A MARGEM DE

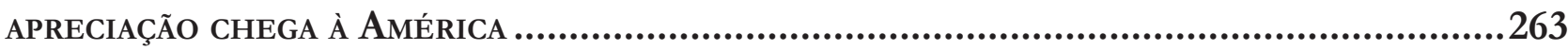

Paloma Morais Corrêa

A "PLENA" LIBERDADE DE EXPRESSÃo E OS DIREITOS HUMANOS: ANÁLISE DA JURISPRUDÊNCIA DA Corte InTeramericana de Direitos Humanos e o Julgamento da ADPF 130 281 Natália Paes Leme Machado

A proteção do meio ambiente no Sistema Interamericano de Direitos Humanos a parTIR DO DIREITO À EDUCAÇÃO.

Augusto César Leite de Resende

Parameters and procedures of the Inter-American System of Human Rights in CHILDREN'S RIGHTS VIOLATION LAWSUITS

Maria Guiomar da Cunha Frota e Pedro Alves Barbosa Neto

Poverty as a Violation of Human Rights: THE CASE OF STREET CHILDREN IN GUATEMALA AND BRAZIL

Paloma Morais Correa

\section{Proteção Internacional dos Direitos Humanos e o Direito Brasileiro}

A LEI N. 11.340/06 E SUAS REPERCuSSõES No CONTRATO INDIVIDUAL DE TRABALHo. Humberto Lima de Lucena Filho e Waldeny Pereira Filho

ORIENTAÇÃo SEXUAL E DISCRIMINAÇão NO AMBIENTE LABORAL

Glaucia Fernanda Oliveira Martins Batalha

NORMAS EDITORIAIS 


\title{
A efetividade do ativismo jurídico transnacional no Sistema Interamericano de Direitos Humanos: uma análise a partir de casos contra o Brasil
}

\author{
The effectiveness of transnational legal \\ activism in the Inter-American System of \\ Human Rights: an analysis from cases against \\ Brazil* $^{*}$
}

\author{
Renata Mantovani de Lima** \\ Lucélia de Sena Alves***
}

\section{Resumo}

Há mais de vinte anos, o Brasil aderiu à Convenção Americana sobre Direitos Humanos o que, desde então, possibilita a litigância transnacional no sistema interamericano da Organização dos Estados Americanos para a proteção dos direitos humanos internacionalmente reconhecidos. O presente trabalho tem como propósito analisar os efeitos provocados pelo ativismo transnacional do sistema em comento na política interna brasileira, a partir dos casos Ximenes Lopes, Penitenciária Urso Branco e Gomes Lund e outros ("Guerrilha do Araguaia"), considerados paradigmáticos, em que o Brasil foi denunciado como violador de direitos humanos, a fim de verificar a efetividade desse tipo de mecanismo.

* Recebido em 27/08/2013

Aprovado em 20/10/2013

** Graduada em Direito pela Faculdade Milton Campos (2003). Mestrado e Doutorado em Direito pela PUC Minas (2006/2011), com pesquisas na Universidade de Pisa - Itália. Professora da Graduação e do Mestrado da Universidade de Itaúna/MG. Professora e Coordenadora do Curso de Direito do Centro Universitário UNA. Consultora jurídica do Grupo Ânima Educação. Contato: renata.mantovani@animaeducacao.com.br.

*** Graduada em Direito pela Universidade de Itaúna/MG (2010). Mestranda em Direitos Fundamentais pela Universidade de Itaúna/ MG. Pesquisadora Senior do projeto "Avaliação da prestação jurisdicional coletiva e individual a partir da judicialização da saúde", do Centro Brasileiro de Estudos e Pesquisas Judiciais (CEBEPEJ). Professora do curso de Direito da Faculdade de Ciências Jurídicas Professor Alberto Deodato, em Belo Horizonte/MG. Advogada.

Palavras-chave: ativismo transnacional - sistema interamericano - direitos humanos - efetividade

\section{Abstract}

For over twenty years, Brazil has been a party to the American Convention on Human Rights and has enabled transnational litigation in the Inter-American System of the Organization of American States for the protection of internationally recognized human rights. This study aims to analyze the effects caused by transnational activism of the Inter-American system in Brazilian domestic politics. The leading cases Ximenes Lopes, Urso Branco Prison and Gomes Lund et al. ("Guerrilla do Araguaia"), , in which Brazil was denounced as a violator of human rights, will be analyzed, in order to verify the effectiveness of this type of mechanism.

Keywords: transnational litigation - Inter-American System - human rights - effectiveness 


\section{INTRODUÇÃO}

O movimento de internacionalização dos direitos humanos, iniciado após a segunda guerra mundial, impulsionou a transformação ideológica da ordem internacional para o reconhecimento da dignidade humana como seu corolário, com o principal objetivo de impedir que atrocidades como aquelas praticadas durante o nazismo não mais ocorressem. Contudo, não bastava que os direitos humanos fossem internacionalmente reconhecidos. Era preciso a criação de mecanismos que assegurassem a sua efetivação. Nasce, então, a ideia de que a tutela dos direitos inerentes à pessoa humana, simplesmente pelo fato de assim o serem, de possuírem essa natureza, transcende o domínio exclusivo do Estado, pertencendo, a partir daí, a toda comunidade internacional.

Os sistemas global e regional de proteção dos direitos humanos foram criados exatamente para garantir a efetivação desses direitos, proporcionando o surgimento do chamado ativismo jurídico transnacional (ou judicialização transnacional), o qual vem, desde os anos 90 , sendo utilizado pelos litigantes de disputas entre Estados, entre indivíduos e Estados, e entre indivíduos para a efetivação de direitos internacionalmente reconhecidos, por intermédio de cortes internacionais ad hoc ou permanentes e tribunais arbitrais. ${ }^{1}$

Devido à extensão do tema, o presente trabalho se limitará à análise do ativismo jurídico transnacional impulsionado por indivíduos e organizações não-governamentais no sistema interamericano de proteção dos direitos humanos em casos em que o Brasil foi acusado de violar esses direitos, a fim de verificar a sua contribuição no processo de (re)organização e (re)politização do país.

\section{Ativismo transnacional}

O ativismo transnacional surge em decorrência da litigância internacional, abrangendo casos de litígios entre Estados, entre indivíduos e Estados e entre indivíduos, além das fronteiras, nos quais envolvam fatos

1 SANTOS, Cecília MacDowell. Ativismo jurídico transnacional e o Estado: reflexões sobre os casos apresentados contra o Brasil na Comissão Interamericana de direitos humanos. SUR - Revista Internacional de Direitos Humanos. São Paulo, no 7, ano 4, p. 27 - 57, 2007, p. 27. que originariamente só poderiam ser levados à jurisdição das cortes internas, porém que, devido a obrigações interestatais firmadas, poderão ser interpostas perante cortes internacionais, permitindo a transformação dos sistemas interno e internacional em um sistema jurídico global, no qual os julgadores aplicarão normas do direito internacional e do direito interno, ou então, uma mistura dos dois. ${ }^{2}$

Cecília MacDowell Santos define o ativismo transnacional como:

"[...] um tipo de ativismo focado na ação legal engajada, através das cortes internacionais ou instituições quase judiciais, em fortalecer as demandas dos movimentos sociais; realizar mudanças legais e políticas internas; reestruturar ou redefinir direitos; e/ou pressionar os Estados a cumprir as normas internacionais e internas de direitos humanos." 3

Segundo $\mathrm{Koh}^{4}$, a moderna litigância transnacional começou após 1946, com o julgamento dos crimes de guerra de Nuremberg e Tóquio, os quais redefiniram a estrutura da litigância internacional, trazendo três principais consequências: a) que os indivíduos não seriam mais somente objetos do direito internacional, mas sim, sujeitos dele; b) que tanto as cortes internas quanto as internacionais teriam competência para determinar direitos e responsabilidades oficiais quando do cometimento de crimes contra a humanidade; e c) a universalização dos direitos humanos através de seus tratados de caráter absoluto. ${ }^{5}$

A possibilidade de utilização desse tipo de instrumento nasce da interdependência entre os Estados, que, na condição de membros da comunidade internacional, decidem, no exercício de sua soberania, cooperar entre si. A respeito da motivação para essa cooperação, a doutrina de BULL estabelece três principais linhas de pensamento: a) a hobbesiana (também denominada realista), segundo a qual a política internacional é entendida como um estado de guerra, em que cada Estado se coloca contra todos os demais e os interesses de um excluem os interesses de todos os outros; b) a kantiana, que identifica, nessa relação interestatal, uma comuni-

2 SLAUGHTER, Anne-Marie. A global community of courts. Haward International Law Journal, v. 44, nº 1, p. 191-219, 2003, p. 192. 3 SLAUGHTER, Anne-Marie. A global community of courts. Haward International Law Journal, v. 44, n 1, p. 191-219, 2003, p. 28.

$4 \mathrm{KOH}$, Harold Honhju. Transnational Public Law litigation. The Yale Law Journal, v.100, p. 2347-2402, 1990.

$5 \mathrm{KOH}$, Harold Honhju. Transnational Public Law litigation. The Yale Law Journal, v.100, p. 2347-2402, 1990, p. 2358-9. 
dade potencial, na qual a natureza essencial da política internacional não está nos conflitos entre os estados, mas nos vínculos sociais transnacionais entre os seres humanos, participantes da comunidade representada pela humanidade; e c) a grociana (também denominada internacionalista), sustentando que a política internacional ocorre dentro de uma sociedade internacional, da qual fazem parte os Estados que têm um interesse comum e, por conta dele, estabelecem limites a seus eventuais conflitos mediante regras e instituições mantidas em comum. ${ }^{6}$

Independentemente da motivação, todo Estado, conforme os ensinamentos de Salem Hikmat Nasser:

\footnotetext{
"sente, em maior ou menor grau, a necessidade de adquirir meios de influenciar os outros, ou seja, de poder. Possui, também necessidade de segurança e uma noção do que seja necessário para conquistálo. (...) Esse é o mundo do "cada um por si" ou talvez até do "cada um contra os outros". Por outro lado, nenhum Estado sobrevive sozinho, é preciso interagir. Porque uns precisam dos outros, eles devem cooperar. A cooperação atende aos interesses de cada um respondendo às necessidades da interdependência."
}

A decisão de cooperação interestatal está ligada, portanto, ao exercício do poder de soberania do Estado, uma vez que este é quem irá ter a palavra final a respeito do que irá ou não cooperar. Não se trata, a nosso ver, de relativização de soberania. ${ }^{8}$ A razão dessa afirmação se sustenta pela concepção que se adota do atributo da soberania, que, segundo Heber Arbuet Vignali, desenvolve-se dentro do direito político de cada Estado, outorgando-lhes um poder supremo e absoluto que subordina as demais vontades e exclui a competência de todo outro poder similar. No âmbito internacional, coexistem muitos soberanos que, ao terem que se relacionar, criam um sistema jurídico de cooperação a partir de compromissos mútuos e obrigações de cumpri-los de boa-fé. ${ }^{9}$ É por conta desse poder que poderão exis-

6 BULL, Hedley. A sociedade anárquica. Disponível em: < http:// www.funag.gov.br/biblioteca/dmdocuments/0158.pdf>. Acesso em: 20 maio 2013, p. 32-3.

7 NASSER, Salem Hikmat. Fontes e normas do Direito Internacional: um estudo sobre a Soft Law. São Paulo: Atlas, 2005, p. 54.

8 Em sentido contrário é o posicionamento de Flávia Piovesan que sustenta que o reconhecimento de mecanismos internacionais de proteção dos direitos humanos por um Estado significa uma relativização do conceito tradicional de soberania. In O Processo de globalização dos direitos humanos. Disponível em: http://www.escolamp.org.br/ARQUIVOS/15_07.pdf. Acesso em: 20 maio 2013.

9 In JIMÉNES DE ARÉCHAGA. Eduardo. Derecho internacional publico. Tomo II. Montevidéo: Fundación de cultura universitária, tir atos estatais contraditórios com os compromissos assumidos internacionalmente, como, por exemplo, as reiteradas violações a direitos humanos ou o descumprimento de recomendações ou decisões provenientes das cortes internacionais, mesmo com a atuação de mecanismos internacionais de coerção.

Portanto, quando os Estados cumprem com uma decisão proveniente dos sistemas internacionais de proteção dos direitos humanos, não abrem mão de sua soberania, mas sim, estão em pleno exercício dela, já que "[..] por livre decisão de suas vontades soberanas, lenta, porém sistematicamente, foram ampliando o campo de suas relações regulamentadas, decididas em comum $[\ldots] \cdot{ }^{\prime 10}$

Entretanto, de uma análise empírica, pode-se perceber que, em muitos casos, a litigância transnacional provoca mudanças nas políticas públicas internas até então empregadas pelos Estados, quando a sua incompatibilidade com os compromissos assumidos por estes em tratados é identificada pelas cortes internacionais.

No que tange aos direitos humanos no sistema interamericano, objeto do presente estudo, pode-se afirmar que o alcance desse novo tipo de ativismo possui uma potencialidade ampla de efetivação, uma vez que, além de remediar abusos individuais, propiciam a (re)politização e (re)legalização das políticas relativas aos direitos humanos. Isso porque a adoção de medidas de natureza administrativa e legislativa é cobrada pelas cortes internacionais e o não cumprimento delas pode gerar consequências negativas no que se refere à cooperação da comunidade internacional em relação àquele Estado violador, contrariando o objetivo de obtenção de poder deste.

\section{O SISTEMA INTERAMERICANO DE PROTEÇÃO DOS DIREITOS HUMANOS E SUA COMPETÊNCIA}

Os mecanismos de proteção dos direitos humanos no âmbito internacional se dividem em dois principais sistemas: o global, realizado pelos órgãos da Organização das Nações Unidas, e o regional, de atuação das

1995, p. 106.

10 ARBUET VIGNALLI, Heber. Los princípios generales de derecho internacional que rigen las relaciones internacionales. In JIMÉNEZ DE ARÉCHAGA. Eduardo. Derecho internacional publico. Tomo I. Montevidéo: Fundación de cultura universitária, 1995, p. 452. 
organizações regionais, entre os quais podemos citar os três principais: o interamericano, o africano e o europeu.

As vantagens dos sistemas regionais são inúmeras, destacando-se a relativa homogeneidade de língua, cultura, tradição, bem como uma maior possibilidade de instituição de mecanismos de monitoramento e de imposição. ${ }^{11}$

O sistema interamericano é um dos sistemas regionais, estabelecendo-se no âmbito da Organização dos Estados Americanos. O processo de criação desse sistema pode ser dividido em três fases. A primeira fase está compreendida entre 1.826 e 1.889, iniciando-se no Congresso do Panamá, ocasião em que foi aprovado, por unanimidade, o Tratado de União Perpétua, Liga e Confederação, dos quais faziam parte a grande Colômbia (formada por Colômbia, Equador, Venezuela e Panamá), México, América Central e Peru. O Tratado estabelecia, entre outras disposições, a criação de uma confederação dos Estados americanos para a consolidação da paz e da defesa solidária dos direitos desses países. A segunda fase inicia-se em 1.889, com uma série de conferências de Ministros das Relações Exteriores de cada Estado-membro da OEA, a cada quatro anos, na qual se destaca, como principal instrumento, a Convenção Relativa aos Direitos do Estrangeiro, celebrada na Cidade do México, em 1.902. Por fim, o marco inicial da terceira fase foi o término da Segunda Guerra Mundial, em 1.945, quando se deu o ponto de partida para o processo de institucionalização jurídica do sistema como é conhecido hoje. ${ }^{12}$

A Organização dos Estados Americanos (OEA) foi estabelecida em 1948, na IX Conferência dos Ministros das Relações Exteriores, realizada em Bogotá, na Colômbia, ocasião em que foi adotada a Carta da OEA e a Declaração Americana dos Direitos e Deveres do Homem (antes mesmo da Declaração Universal dos Direitos Humanos pela Assembleia Geral da ONU). ${ }^{13}$ Entretanto, somente em 1.978, com a entrada em vigor da Convenção Americana sobre Direitos Humanos, de 1969, ocorreu o grande passo para a efetivação dos direitos humanos no âmbito regional, uma vez que os principais órgãos deste sistema (a Comissão In-

11 SMITH, Rhona K. M. Texbook on international human rights. Oxford: Oxford University Press, 2012, p. 87.

12 HANASHIRO, Olaya Sílvia Machado Portella. O sistema interamericano de proteção aos direitos humanos. São Paulo: Editora da Fapesp, 2001, p. 25-9.

13 HANASHIRO, Olaya Sílvia Machado Portella. O sistema interamericano de proteção aos direitos humanos. São Paulo: Editora da Fapesp, 2001, p. 29-30. teramericana e a Corte Interamericana) passaram a atuar de forma mais abrangente. ${ }^{14}$

A Comissão Interamericana exerce um papel primordialmente mediador, representando todos os Estados-membros da OEA, com atribuições previstas nos artigos 41 a 43 da Convenção Americana sobre Direitos Humanos (Pacto de São José da Costa Rica). Qualquer pessoa está legitimada a peticionar à Comissão para informar possíveis casos de violação a direitos humanos praticada pelos seus membros, cabendo a esta solucionar de forma amistosa o caso apresentado, através de recomendações e solicitações e, caso frustrem as tentativas de solução amigável, a Comissão redigirá um relatório, submetendo-o, logo em seguida, à Corte Interamericana, conforme estabelecem os artigos 44 a 51 da Convenção Interamericana.

Os requisitos de admissibilidade de uma petição à Comissão estão estabelecidos no art. 46, da Convenção Americana, destacando-se: o esgotamento dos recursos da jurisdição interna, a interposição dentro do prazo de seis meses contados de sua notificação e a inexistência de pendência em qualquer outro processo de solução internacional. No entanto, esses dois primeiros requisitos não serão considerados caso inexistam mecanismos de proteção interna para a suposta violação ou caso tenha ocorrido a demora injustificada na tentativa de resolução interna.

Já a Corte Interamericana é o órgão jurisdicional do sistema interamericano e possui suas atribuições previstas nos arts. 61 a 65, da Convenção, sendo competente para as controvérsias que envolvam casos de interpretação e aplicação das disposições da mesma convenção, em que figurem Estados-Partes que tenham se submetido à sua jurisdição, propostos diretamente pelos Estados, ou que tenham sido encaminhados pela Comissão Interamericana.

A possibilidade de interposição, por parte do indivíduo, de petição no sistema interamericano significa um enorme avanço para o Direito Internacional, no sentido de fortalecimento da posição dos particulares nesse plano. ${ }^{15}$ Esse fortalecimento é sustentado por Pasqualucci, como mudança do status dos indivíduos de

14 TRINDADE, Antônio Augusto Cançado. A evolução do sistema interamericano de proteção dos direitos humanos: uma análise crítica. Revista de Informação Legislativa, ano 19, no 73, jan./mar.1982, p. 114.

15 TRINDADE, Antônio Augusto Cançado. O esgotamento de recursos internos no direito internacional. Brasília: UnB, 1997, p. 238. 
objeto para sujeito de direito internacional. ${ }^{16}$ Porém, o posicionamento acima exarado ainda é controverso, conforme sustentam Pellet, Dinh e Daillier:

"Não há dúvida que as pessoas privadas são
abrangidas por um grande número de normas
internacionais quer elas lhes confiram vantagens
quer lhes imponham sujeições.

Mas não se conclui que, por isso, as pessoas privadas sejam sujeitos de direito internacional já que na maioria dos casos o Estado faz de intermediário entre elas e o direito internacional." ${ }^{17}$

Deixando as controvérsias de lado, é inegável que a possibilidade de participação de qualquer pessoa no sistema interamericano promove o acesso a uma ordem jurídica e política mais justa, na medida em que amplia os recursos de proteção dos direitos humanos.

Em sua atuação, a Corte declarará a violação a direitos humanos pelo Estado, reconhecendo a sua responsabilidade e determinando que ele repare, através de medidas que entenda necessárias, ou mediante justa indenização, os danos a que tenham sofrido as vítimas.

Apesar de ter atribuído à Corte um caráter jurisdicional, a Convenção Americana não estabeleceu um procedimento formal para a coerção do Estado para o cumprimento de suas decisões, porém estabeleceu em seu artigo 65 que:

"A Corte submeterá à consideração da Assembleia Geral da Organização, em cada período ordinário de sessões, um relatório sobre as suas atividades no ano anterior. De maneira especial, e com as recomendações pertinentes, indicará os casos em que um Estado não tenha dado cumprimento a suas sentenças."

Essa disposição, conforme ressalta Thomas Buergenthal, ${ }^{18}$ permite que a Corte informe à Assembleia Geral da OEA situações que envolvam descumprimento de suas decisões para que esta adote as medidas políticas que entenda necessárias. Além disso, promove a tomada de conhecimento dos outros Estados-Partes acerca do (baixo) grau de comprometimento de cada Estado com relação aos compromissos internacionalmente assumidos, o que acarreta consequências políticas no processo de cooperação entre eles.

16 PASQUALUCCI, Jo M. The practice and procedure of the InterAmerican Court of Human Rights. Cambridge: Cambridge University Press, 2003, p. 1.

17 DINH, Nguyen Quoc; DAILLIER, Patrick; PELLET, Alain. Direito Internacional Público. Portugal: Fundação Calouste Gulbenkian, 1999, p. 579.

18 BUERGENTHAL, Thomas. The inter-american court of human rights. The American Journal of International Law, v. 76, p. 231-245, 1.982 , p.241.
Além dessas atribuições, a Comissão e a Corte podem adotar medidas de urgência em desfavor dos Estados supostamente violadores, sendo elas as medidas cautelares, de atribuição da Comissão, e as medidas provisórias, de competência da Corte, as quais visam a determinar que os Estados cumpram essas medidas, antes mesmo de se findarem os procedimentos estabelecidos na Convenção, quando estiver em risco o direito à vida. Entretanto, conforme ressalta Felipe Gonzáles, a partir dos anos 90, a utilização desses mecanismos se ampliou de forma considerável para abarcar diversos outros assuntos, como a tutela dos direitos das crianças e dos adolescentes, condições carcerárias, lesões ao devido processo legal e direitos à propriedade. ${ }^{19}$

\section{A Responsabilidade do Estado POR VIOLA- ÇÕES DE DIREITOS HUMANOS}

O estudo da proteção dos direitos humanos remete, inevitavelmente, ao estudo da responsabilidade do Estado por atos que contrariam os compromissos por ele assumidos internacionalmente, uma vez que o simples reconhecimento de direitos não promove a sua efetivação.

Atualmente, tanto a doutrina quanto a jurisprudência consideram a responsabilidade internacional do Estado como instituição, princípio geral do direito e obrigação jurídica, segundo a qual o Direito Internacional reage às violações de suas normas. ${ }^{20}$

A responsabilidade internacional dos Estados é elemento corolário das relações interestatais. Sem ela não se poderia garantir o cumprimento dos compromissos assumidos pelos Estados. Este princípio é tão antigo como o da igualdade entre os Estados, já que estes, como iguais, devem admitir esta qualidade tanto em relação aos seus direitos quanto aos seus deveres, ${ }^{21}$ fundamentando-se, principalmente, no princípio da igualdade soberana dos Estados, segundo a qual um Estado não pode reivindicar o cumprimento de normas internacionais se não as estiver cumprindo. ${ }^{22}$

19 GONZÁLEZ, Felipe. As medidas de urgência no sistema interamericano de direitos humanos. SUR - Revista Internacional de Direitos Humanos. São Paulo, v. 7, no 13, p. 50-198, 2010, p. 66.

20 RAMOS, André de Carvalho. Responsabilidade internacional por violação de direitos humanos. Rio de Janeiro: Renovar, 2004, p. 74.

21 DINH, Nguyen Quoc; DAILLIER, Patrick; PELLET, Alain. Direito internacional public. Tradução Vítor Marques Coelho. $4^{\mathrm{a}}$ edição. Lisboa: Fundação Calouste Gulbenkian, 1992, p. 680.

22 RAMOS, André de Carvalho. Responsabilidade internacional 
André de Carvalho Ramos leciona que, de acordo com a prática internacional, são três os elementos da responsabilidade internacional do Estado: a) a existência de um ato internacionalmente ilícito; b) o resultado lesivo; e c) o nexo causal entre o fato e o resultado lesivo. ${ }^{23}$ Presentes esses elementos, haverá o dever de repará-los, bem como o de adotar medidas que impeçam a sua reincidência.

A ilicitude do ato, consoante as regras do direito internacional, não sofrem influência do direito interno, uma vez que, de acordo com o art. $3^{\circ}$ do Projeto da Comissão de Direito Internacional das Nações Unidas sobre Responsabilidade Internacional dos Estados, a caracterização de um ato de um Estado como internacionalmente ilícito é regida pelo Direito Internacional e esta não é afetada pela caracterização do mesmo ato como lícito pelo direito interno. ${ }^{24}$

Ao ratificarem os tratados de direitos humanos, os Estados assumem obrigações convencionais de proteção a todos os direitos reconhecidos, além de obrigações gerais, como a de adequar o ordenamento jurídico interno à referida norma internacional, requerendo, portanto, a adoção de legislação necessária para efetivar aqueles direitos, em total consonância com as normas internacionais, atingindo essa responsabilidade os poderes Legislativo, Executivo e Judiciário, bem como os seus órgãos e agentes. ${ }^{25} \mathrm{~A}$ regra contida no art. $3^{\circ}$, portanto, torna-se especialmente relevante para a verificação, por exemplo, nos casos de violação de direitos humanos, da conformidade das normas internas às de Direito Internacional. ${ }^{26}$

A Constituição de 1988 atribuiu especial valor aos tratados de direitos humanos ao prever o princípio da prevalência dos direitos humanos como regente das relações internacionais, bem como pelo disposto no artigo $5^{\circ}, \S 2^{\circ}$, que estabeleceu que os direitos e garantias previstos naquele capítulo não excluem aqueles previstos nos tratados internacionais a que o Brasil faça parte.

do Estado por violação de direitos humanos. Revista CEJ, Brasília, n. 29, p. 53-63, abr./jun. 2005, p. 54.

23 RAMOS, André de Carvalho. Responsabilidade internacional do Estado por violação de direitos humanos. Revista CEJ, Brasília, n. 29, p. 53-63, abr./jun. 2005, p. 55.

24 In SALIBA, Aziz Tuffi. Legislação de direito internacional. São Paulo: Rideel, 2013, p. 416.

25 TRINDADE, Antônio Augusto Cançado. O direito internacional em um mundo em transformação. Rio de Janeiro: Renovar, 2002, p. 640-50. 26 International Law commission. Draft articles on Responsibility of States for Internationally Wrongful Acts, with commentaries, 2001. Disponível em < http://untreaty.un.org/ilc/texts/instruments/english/commentaries/9_6_2001.pdf>. Acesso em 20 maio 2013.
Embora existam opiniões contrárias, entende-se que o disposto no referido parágrafo é suficiente para que se interprete que os tratados que versam sobre direitos humanos possuem valor constitucional, configurando, como consequência, cláusula pétrea, conforme dispõe o artigo $60, \$ 4^{\circ}$, IV, da Constituição vigente. Entretanto, o atual entendimento do Supremo Tribunal Federal, exarado quando da votação do Recurso Extraordinário no 466.343 , assevera que os tratados internacionais de direitos humanos subscritos pelo Brasil teriam valor supralegal, localizando-se abaixo da Constituição e acima da legislação infraconstitucional.

Contudo, os tratados sobre direitos humanos que forem aprovados em cada casa do Congresso Nacional por três quintos dos votos, em dois turnos, têm valor de emenda constitucional, conforme prevê o parágrafo $3^{\circ}$, ainda do artigo $5^{\circ}$.

\section{Os casos apresentados contra o Brasil NO SISTEMA INTERAMERICANO}

Desde 1998 o Brasil se submete à jurisdição da Corte Interamericana, no entanto, antes mesmo desse ano, o país foi denunciado ao sistema interamericano em diversas ocasiões, conforme poderá ser verificado no quadro abaixo.

Número de petições apresentados contra $o$ Brasil junto à Comissão Interamericana

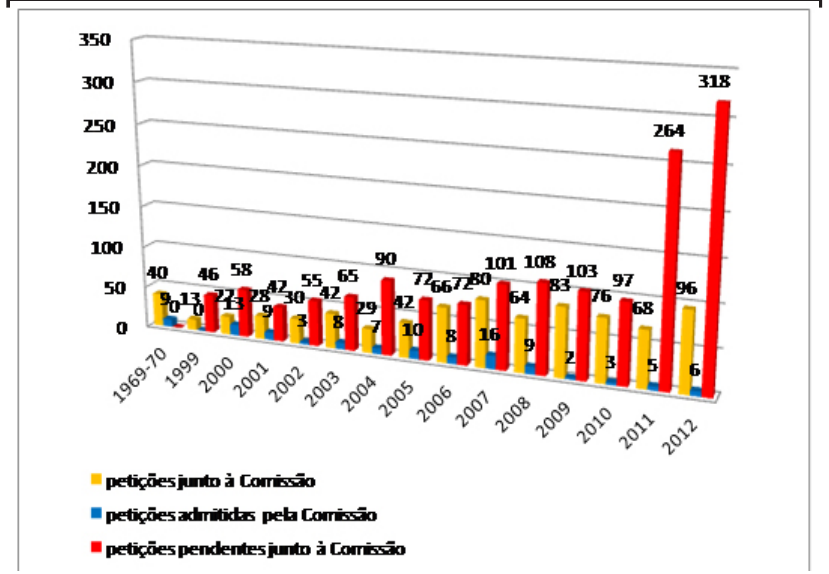

Fonte: elaboração própria a partir dos dados contidos no site da Comissão Interamericana de Direitos Humanos. ${ }^{27}$

Como se pode constatar, o número de petições à Comissão Interamericana, que, em 1999 totalizava 13 petições, vem evoluindo significativamente ao longo

27 Disponível em: < http://www.oas.org/pt/cidh/>. Acesso em 15 jul 2013. 
dos anos, sendo que em 2008 atingiu o seu maior número, de 108 petições. Essa quantidade cada vez mais crescente faz também aumentar o número de petições pendentes na Comissão para a análise de sua aceitação ou rejeição, o que irá influenciar, consequentemente, no grau de efetividade de todo o sistema.

Serão analisados, abaixo, três casos considerados paradigmáticos para ilustrar os efeitos gerados pelo do ativismo transnacional perante o sistema interamericano no direito interno brasileiro.

\section{O Caso Ximenes Lopes vs. Brasil}

Damião Ximenes Lopes ${ }^{28}$ sofria de transtorno mental e foi internado por sua mãe, Dona Albertina, em 01 de outubro de 1999, devido a uma forte crise, na Casa de Repouso dos Guararapes, em Sobral, no estado do Ceará. Entretanto, quatro dias mais tarde, Dona Albertina retornou ao estabelecimento para visitar seu filho, sendo impedida pelos funcionários do estabelecimento, sob a alegação de que Damião não estaria em condições de receber visitas. Inconformada, Dona Albertina começou a gritar e chamar pelo nome do filho, o qual apareceu na sua frente em estado deplorável, cheio de hematomas e ferimentos, porém, como não tinha condições de levar o filho de volta para a casa, que ficava a $72 \mathrm{~km}$ de Sobral, deixou o filho internado. Assim que chegou em casa, na cidade de Varjota, Dona Albertina recebeu a notícia de que seu filho havia falecido em decorrência de insuficiência cardiorrespiratória.

Desconfiada do diagnóstico fornecido pela referida casa de repouso, em virtude do que havia presenciado dias antes, a mãe de Damião e seus familiares solicitaram do instituto médico legal da capital do estado, Fortaleza, outra avaliação, na qual foi constatado, pelo mesmo médico que havia realizado a necropsia na Casa de Repouso dos Guararapes, que Damião havia falecido em decorrência de causa indeterminada. Por conta dessa afirmação, as autoridades policiais não demonstraram muito interesse em averiguar o ocorrido e, com receio de que a morte de Damião ficasse impune, a irmã dele, Irene Ximenes Lopes Miranda, em 22 de novembro de 1999, denunciou o Brasil junto à Comissão Interamericana por violações a direitos humanos.

Em 14 de dezembro de 1999, a Comissão recebeu a petição de Irene, bem como solicitou informações ao

28 Os dados completos sobre este caso estão disponíveis em: $<\quad$ http://www.cidh.oas.org/demandas/12.237\%20Ximenes $\% 20$ Lopez\%20Brasil\%201oct04.pdf>. Acesso em 15 jul 2013.
Brasil a serem prestadas no prazo de noventa dias, o que não foi cumprido. Quase três anos depois, em 9 de outubro de 2002, a Comissão considerou a falta de resposta do Estado brasileiro e deu início ao procedimento de $n^{\circ} 12.237$ e colocou à disposição das partes para a resolução amistosa, em maio de 2003.

Como não houve qualquer pronunciamento do Brasil para o caso, em 8 de outubro de 2003, a Comissão considerou, no Relatório de Mérito 43/03, que o país havia violado vários dispositivos da Convenção Americana, como a proteção da integridade pessoal, direito à vida, proteção e garantias judiciais, determinando ao país a adoção de várias medidas para repará-las, encaminhando-as, em 31 de dezembro de 2003, ao Estado brasileiro para o seu cumprimento em dois meses. Somente após essa notificação é que o Estado brasileiro se manifestou, pela primeira vez, no referido procedimento, em 17 de março de 2004, requerendo a dilação do prazo para a implementação das recomendações feitas pela Comissão, tendo esta decidido submeter o caso à Corte, em 30 de setembro de 2004.

$\mathrm{O}$ procedimento que se iniciou em $1^{\circ}$ de outubro de 2004, na Corte, findou-se em 4 de julho de 2006, com a condenação unânime do Brasil pelas violações praticadas contra o senhor Damião Ximenes Lopes e seus familiares, determinando o pagamento das devidas indenizações pecuniárias a esses últimos, bem como a adoção de diversas medidas em relação às políticas públicas para a saúde mental e judiciais, para o processamento e punição dos responsáveis, em prazo razoável.

Apesar dessa condenação, somente em 2010 a sentença do processo cível (n²00001730797-0) transitou em julgado, e a do criminal ( $\left.\mathrm{n}^{\circ} 2000.0172 .9186-1\right)$ transitou em julgado em 31de agosto de 2011. ${ }^{29}$

\section{O Caso Urso Branco vs. Brasil}

Em 2002, a Comissão Interamericana recebeu petição em favor dos internos da Casa de Detenção José Mário Alves, também conhecida como Penitenciária Urso Branco ${ }^{30}$, em Porto Velho, Rondônia, sob a alegação de que vários detentos haviam sido brutalmente

29 Dados disponíveis em <http://www4.tjce.jus.br/sproc2/paginas/sprocprincipal.asp>. Acesso em 20 maio 2013.

30 Os dados completos sobre este caso estão disponíveis em: < http://www.corteidh.or.cr/docs/casos/articulos/Seriec_149_esp. pdf $>$. Acesso em 20 jul 2013. 
assassinados enquanto estavam sob a custódia do Estado brasileiro. $\mathrm{O}$ fato ocorreu em $1^{\circ}$ de janeiro de 2002, quando a direção do estabelecimento procedeu à relocação de 60 detentos que se encontravam em celas denominadas "especiais", em razão de eles terem cometido crimes considerados imorais e, por isso, caso colocados em contato com os demais internos, poderiam correr risco de vida. Esse grupo foi dividido em grupos de cinco e colocados junto com os detentos de celas comuns.

No mesmo dia, por volta das $21 \mathrm{~h}$, deu-se início ao homicídio sistemático dos presos provenientes das celas de segurança pelos próprios detentos das celas comuns, sem que os agentes penitenciários do estabelecimento adotassem qualquer providência para impedi-los. No dia seguinte, foi relatado que quarenta e cinco corpos haviam sido encontrados, sendo que em alguns deles havia sinais de decapitação e mutilação, além de várias marcas de chuchos $^{31}$. Apesar desse relatório, o Governo do Estado informou à imprensa a morte de vinte e sete internos. Após esse episódio, mais cinco detentos ainda foram mortos.

Em 14 de março do mesmo ano, a Comissão solicitou ao Estado a adoção de medidas para a proteção da vida e integridade dos reclusos de Urso Branco, porém, outros cinco foram brutalmente assassinados, totalizando trinta e sete mortes.

Em decorrência disso, a Comissão solicitou à Corte a determinação de medidas provisórias ao Estado brasileiro, a fim de impedir que outras mortes ocorressem, sendo tais medidas deferidas pelo Órgão, em 18 de junho de 2002. Determinou-se, dentre outras medidas, que o país informasse, no prazo de quinze dias, todos os nomes dos reclusos naquele estabelecimento prisional, bem como adotasse medidas para a investigação e responsabilização dos responsáveis pelas mortes relatadas.

Entretanto, vários outros episódios foram relatados pela Comissão. Entre os dias 23 e 27 de junho, trezentos e oito presos foram colocados de castigo no pátio do estabelecimento prisional, nus e sem comida. Além disso, tiveram seus cabelos raspados e foram espancados, o que provocou a determinação pela Corte, em 29 de agosto de 2002, de outras medidas provisórias em desfavor do Estado brasileiro.

Outras cinco resoluções determinaram medidas provisionais a serem cumpridas pelo Brasil (22 de abril de

31 Os chuchos são armas cortantes penetrantes fabricadas pelos próprios detentos.
2004; 07 de julho de 2004; 21 de setembro de 2005; 02 de maio de 2008; e 25 de novembro de 2009), tendo sido arquivado o expediente pela Corte, em 25 de agosto de 2011, em decorrência de um acordo firmado entre a Comissão e o Estado, no qual este se comprometeu a implementar as políticas relativas à infraestrutura, qualificação do pessoal, apuração dos fatos e responsabilização e aperfeiçoamento dos serviços, estabelecidas no "Pacto para melhoria do sistema prisional do estado de Rondônia e levantamento das medidas provisórias outorgadas pela Corte Interamericana de Direitos Humanos". ${ }^{32}$

\section{O Caso Gomes Lund e outros ("Guerrilha do Araguaia") vs. Brasil}

Em 7 de agosto de 1995, o Centro pela Justiça e o Direito Internacional (CEJIL) e a Human Rights Watch/Americas, peticionaram à Comissão Interamericana denunciando o Brasil por violações a direitos humanos no contexto da ditadura militar ocorrida no país entre 1964 e 1985. A responsabilidade do Estado foi pleiteada em consequência da detenção arbitrária, tortura e desaparecimento forçado de 70 pessoas, pertencentes ao movimento guerrilheiro denominado "Guerrilha do Araguaia", formado pelo Partido Comunista do Brasil, que tinha como objetivo instaurar o socialismo no país.

A petição foi recebida pela Comissão em 6 de março de 2008, sendo o Brasil notificado em 21 de novembro do mesmo ano acerca de várias recomendações no sentido de viabilizar a persecução penal dos responsáveis pelos graves crimes cometidos, promovendo, inclusive, alterações legais a fim de que a Lei da Anistia não continuasse a impedir o processamento e julgamento de seus autores.

Por entender insatisfatório o cumprimento de suas recomendações, a Comissão submeteu o caso à Corte em 26 de março de 2009, a qual condenou o Brasil, em 24 de novembro de 2010, ao pagamento de indenizações às famílias das vítimas pelas violações narradas pelos peticionários, bem como declarou a incompatibilidade da Lei da Anistia com as disposições da Convenção Americana, concluindo que o país também violou a obrigação de adequação de suas normas internas com esta.

32 Caso disponível em: <http://corteidh.or.cr/docs/medidas/ urso_se_10_ing.pdf>. Acesso em 15 jul 2013. 
O Caso Gomes Lund e outros foi o primeiro em que o Brasil obteve condenação diametralmente oposta à sua jurisprudência até então pacificada, uma vez que as disposições que impedem investigação e sanção dos responsáveis por violações a direitos humanos durante o período da ditadura militar da Lei $\mathrm{n}^{\circ}$ 6.683/79 (Lei de Anistia) foram declaradas incompatíveis com a Convenção Interamericana e declarada sem efeito perante a Corte e, consequentemente, não impediu a condenação do Brasil às devidas reparações.

O juiz ad hoc Roberto de Figueiredo Caldas proferiu voto fundamentado em separado, classificando os crimes perpetrados no caso como de lesa-humanidade, ressaltando que eles devem ser tratados de forma diversa, no sentido de que não deveria ocorrer prescrição ou anistia. Além disso, criticou a postura omissa do Estado ao não ratificar, após quarenta e dois anos de adoção, no âmbito internacional, da Convenção sobre Imprescritibilidade dos Crimes de Guerra e dos Crimes de Lesa-Humanidade, atribuindo-a à pressão política dos militares que participaram daquelas atrocidades. ${ }^{33}$

Até o presente momento, além do Caso Ximenes Lopes, julgado em 04 de julho de 2006, e do Caso Gomes Lund e outros, julgado em 24 de novembro de 2010, o Brasil foi condenado em mais dois por violações a direitos humanos, sendo eles o Caso Escher e outros, julgado em 06 de julho de 2009; e o Caso Garibaldi, julgado em 23 de setembro de 2009.

\section{Os REFLEXOS INTERNOS DO ATIVISMO TRANSNACIONAL NO ÂMBITO JURÍDICO INTERNO BRASILEIRO}

Com base no art. $2^{\circ}$ da Convenção Americana sobre Direitos Humanos, pode-se afirmar que a significação e o alcance de um tratado como este podem ser medidos por seus possíveis efeitos jurídicos no direito interno dos Estados-parte. ${ }^{34}$

33 O inteiro teor da decisão está disponível em: < http://www. corteidh.or.cr/docs/casos/articulos/seriec_219_por.pdf $>$. Acesso em 15 jul 2013.

34 TRINDADE, Antônio Augusto Cançado. A evolução do sistema interamericano de proteção dos direitos humanos: uma análise crítica. Revista de Informação Legislativa, ano 19, nº 73, jan./mar.1982, p. 116.
A partir dos casos analisados neste estudo, pode-se constatar que a litigância no sistema interamericano influencia sobremaneira não só as políticas públicas empregadas pelo governo brasileiro, através da atuação de sua Comissão e de sua Corte, uma vez que, seja por conta de suas recomendações ou condenações, foram derrogados ou modificados inúmeros dispositivos legais que impediam a efetivação dos direitos humanos. ${ }^{35}$ Além disso, como sustenta PASQUALUCCI ${ }^{36}$, essa atuação não contribui somente para a modificação das práticas políticas do país, mas também para a evolução do próprio Direito Internacional, na medida em que suas decisões promovem a evolução da interpretação dos próprios direitos humanos.

A condenação no Caso Ximenes Lopes foi histórica, uma vez que foi a primeira em que o Brasil foi condenado no sistema interamericano e foi a primeira a tratar de questões acerca da saúde mental. Os efeitos positivos do caso, segundo ROSATO e CORREIA ${ }^{37}$ foram: o descredenciamento e desativação da Casa de Repouso Guararapes, na qual Damião foi morto; a criação de um centro de saúde mental que leva o nome de Damião Ximenes Lopes, no Estado do Ceará; a edição da Lei n ${ }^{\circ}$ 10.216/2001, que trata das políticas públicas para a proteção dos direitos das pessoas com transtornos mentais, considerada um marco para a evolução dessas políticas, apesar de ainda serem consideradas insatisfatórias.

O Caso Urso Branco, apesar de ainda não ter chegado à jurisdição da Corte Interamericana, cumpriu com algumas das recomendações da Comissão, bem como com as medidas provisórias da Corte, entre as quais se destacam: a ampliação do referido presídio; capacitação de seus agentes penitenciários pela Escola de Formação, Qualificação e Capacitação de Servidores Penitenciários; e a assinatura do "Pacto para melhoria do sistema prisional do estado de Rondônia e levantamento das medidas provisórias outorgadas pela Corte Interamericana de Direitos Humanos.”

35 ROSATO, Cássia Maria; CORREIA, Ludmila Cerqueira. Caso Damião Ximenes Lopes: mudanças e desafios após a primeira condenação do Brasil pela Corte Interamericana de Direitos Humanos. SUR - Revista Internacional de Direitos Humanos. São Paulo, v. 8, n 15, p. 93-113, 2011, p. 103.

36 PASQUALUCCI, Jo M. The practice and procedure of the InterAmerican Court of Human Rights. Cambridge: Cambridge University Press, 2003, p. 329.

37 ROSATO, Cássia Maria; CORREIA, Ludmila Cerqueira. Caso Damião Ximenes Lopes: mudanças e desafios após a primeira condenação do Brasil pela Corte Interamericana de Direitos Humanos. SUR - Revista Internacional de Direitos Humanos. São Paulo, v. 8, no 15, p. 93-113, 2011, p. 103. 
No caso Gomes Lund e outros ("Guerrilha do Araguaia"), essas mudanças também ocorreram de forma expressiva, principalmente com a criação da Comissão da Verdade, pela Lei $\mathrm{n}^{\circ}$ 12.528, de 16 de maio de 2012, a qual visa a apurar as violações a direitos humanos praticadas no período compreendido entre 18 de setembro de 1946 e 5 de outubro de 1988, cuja instituição foi pleiteada à Corte pelos representantes dos familiares das vítimas do caso. Segundo Cláudio Fonteles, integrante da Comissão da Verdade, em seu relatório final, previsto para o final de 2014, a Comissão vai recomendar a revisão da Lei de Anistia, a fim de permitir o julgamento e punição dos autores dos crimes praticados durante a ditadura militar. ${ }^{38}$

Contudo, como demonstram os relatórios da Corte Interamericana, bem como os casos citados no presente artigo, o Brasil ainda protela o cumprimento das medidas por ela impostas e, muitas vezes, as cumpre de forma parcial, fazendo com que as violações perdurem por muito tempo.

\section{Considerações Finais}

$\mathrm{O}$ ativismo transnacional viabilizado pelos mecanismos de proteção do sistema interamericano de proteção dos direitos humanos constitui verdadeiras garantias aos indivíduos e certamente contribui para a efetivação desses direitos, já que, com a atuação da Comissão e da Corte interamericanas, foi possível a mudança de políticas públicas violadoras de direitos humanos.

As decisões proferidas pela Corte Interamericana contribuem tanto para a evolução dos mecanismos de proteção dos direitos humanos quanto para a do próprio Direito Internacional regional.

Apesar dos avanços, constata-se que o sistema interamericano possui algumas barreiras que limitam a sua efetividade, uma vez que ainda depende da vontade dos Estados-parte para a internalização das normas internacionais de direitos humanos e, estes, apesar de terem se comprometido internacionalmente assim não o procedem.

Assim, faz-se necessário o fortalecimento dos meios de coerção para que o cumprimento das medidas deter-

38 Entrevista concedida ao Jornal O Globo. Disponível em http:/ / oglobo.globo.com/pais/comissao-da-verdade-vai-recomendar-revisao-da-lei-da-anistia-8440532. Acesso em 20 maio 2013. minadas pelos órgãos do sistema interamericano ocorra de forma mais célere e eficaz.

\section{ReferênCIAS}

BUERGENTHAL, Thomas. The inter-american court of human rights. The American Journal of International Law, v. 76, p. 231-245, 1.982.

BULL, Hedley. A sociedade anárquica. Disponível em: $<\quad$ http://www.funag.gov.br/biblioteca/dmdocuments/0158.pdf>. Acesso em: 20 maio 2013.

DINH, Nguyen Quoc; DAILLIER, Patrick; PELLET, Alain. Direito Internacional Público. Portugal: Fundação Calouste Gulbenkian, 1999.

GONZÁLEZ, Felipe. As medidas de urgência no sistema interamericano de direitos humanos. SUR - Revista Internacional de Direitos Humanos. São Paulo, v. 7, $\mathrm{n}^{\circ}$ 13, p. 50-198, 2010.

HANASHIRO, Olaya Sílvia Machado Portella. O sistema interamericano de proteção aos direitos humanos. São Paulo: Editora da Fapesp, 2001.

JIMÉNEZ DE ARÉCHAGA. Eduardo. Derecho internacional publico. Tomo I. Montevidéo: Fundación de cultura universitária, 1995.

JIMENES DE ARÉCHAGA. Eduardo. Derecho internacional publico. Tomo II. Montevidéo: Fundación de cultura universitária, 1995.

$\mathrm{KOH}$, Harold Honhju. Transnational Public Law litigation. The Yale Law Journal, v.100, p. 2347-2402, 1990.

NASSER, Salem Hikmat. Fontes e normas do Direito Internacional: um estudo sobre a Soft Law. São Paulo: Atlas, 2005.

PASQUALUCCI, Jo M. The practice and procedure of the Inter-Amrican Court of Human Rights. Cambridge: Cambridge University Press, 2003.

PIOVESAN, Flávia. O Processo de globalização dos direitos humanos. Disponível em: http://www.escolamp.org. br/ARQUIVOS/15_07.pdf. Acesso em: 20 maio 2013.

RAMOS, André de Carvalho. Responsabilidade internacional porviolação de direitos humanos. Rio de Janeiro: Renovar, 2004.

RAMOS, André de Carvalho. Responsabilidade internacional do Estado por violação de direitos humanos. Revista CEJ, Brasília, n. 29, p. 53-63, abr./jun. 2005. 
ROSATO, Cássia Maria; CORREIA, Ludmila Cerqueira. Caso Damião Ximenes Lopes: mudanças e desafios após a primeira condenação do Brasil pela Corte Interamericana de Direitos Humanos. SUR - Revista Internacional de Direitos Humanos. São Paulo, v. 8, no 15, p. 93-113, 2011.

SALIBA, Aziz Tuffi. Legislação de direito internacional. São Paulo: Rideel, 2013.

SANTOS, Cecília MacDowell. Ativismo jurídico transnacional e o Estado: reflexões sobre os casos apresentados contra o Brasil na Comissão Interamericana de direitos humanos. SUR - Revista Internacional de Direitos Humanos. São Paulo, no 7, ano 4, p. 27 - 57, 2007.

SLAUGHTER, Anne-Marie. A global community of courts. Haward International Law Journal, v. 44, $\mathrm{n}^{\mathrm{o}} 1$, p. 191-219, 2003.

SMITH, Rhona K. M. Texbook on international buman rights. Oxford: Oxford University Press, 2012.

TRINDADE, Antônio Augusto Cançado. A evolução do sistema interamericano de proteção dos direitos humanos: uma análise crítica. Revista de Informação Legislativa, ano $19, \mathrm{n}^{\mathrm{o}} 73$, jan./mar.1982.

TRINDADE, Antônio Augusto Cançado. O direito internacional em um mundo em transformação. Rio de Janeiro: Renovar, 2002.

TRINDADE, Antônio Augusto Cançado. O esgotamento de recursos internos no direito internacional. Brasília: UnB, 1997. 
Para publicar na Revista de Direito Internacional, acesse o endereço eletrônico www.rdi.uniceub.br ou www.brazilianjournal.org.

Observe as normas de publicação, para facilitar e agilizar o trabalho de edição. 